\title{
Genotoxicity and Cytotoxicity Assessment of Graphene Oxide Nanosheets on HT29 Cells
}

\author{
Masoumeh Heshmati, ${ }^{1,}$ Sajedeh Hajibabae, ${ }^{1}$ and Nooshin Barikrow ${ }^{1}$ \\ ${ }^{1}$ Department of Molecular and Cellular Sciences, Faculty of Advanced Sciences and Technology, Pharmaceutical Sciences Branch, Islamic Azad University, Tehran, Iran \\ "Corresponding author: Masoumeh Heshmati, Department of Molecular and Cellular Sciences, Faculty of Advanced Sciences and Technology, Pharmaceutical Sciences Branch, \\ Islamic Azad University, Tehran, Iran. Fax: +98-2122640051, E-mail: heshmati.cmb@gmail.com
}

Received 2017 September 27; Accepted 2018 March 06.

\begin{abstract}
Background: Graphene and graphene-related materials are broadly applied for biomedical purposes due to their unique properties. However, little information is available on their toxicity and biocompability, thus it is necessary to assess their safety. We investigated the cytotoxic and genotoxic effects of graphene oxide nanosheets (GOs) on HT29 cells.

Methods: GOs were synthesized by oxidation of natural graphite flakes according to the modified Hummers method. GOs were characterized using IR spectroscopy and TEM. Cytotoxicity and genotoxicity of GOs on HT29 cells were evaluated in the range of 10 - $250 \mu \mathrm{g} / \mathrm{mL}$ after 24,48 and 72 hours of treatment using MTT assay and in the range of $10-50 \mu \mathrm{g} / \mathrm{mL}$ after $48 \mathrm{~h}$ by micronucleous assay.

Results: The results of IR indicate that the graphite is successfully oxidized. The GOs were found to be $3-6 \mu \mathrm{m}$ in length and $\leq 1 \mathrm{~nm}$ in diameter by TEM. The half maximal inhibitory concentration $\left(\mathrm{IC}_{50}\right)$ in different doses were calculated at $50 \mu \mathrm{g} / \mathrm{mLby}$ trypan blue dye exclusion assay. The results of MN assay showed a significant increase in DNA damage and MN formation in GOs treated samples as compared with the control sample $(\mathrm{P}<0.05)$.

Conclusions: Concentration, shape, time and physicochemical properties GOs like size, shape, agglomeration rate and surface chemistry play important roles in inducing cytotoxicity and genotoxicity of treated cells.
\end{abstract}

Keywords: Graphene Oxide Nanosheet, Genotoxicity, Cytotoxicity

\section{Background}

Significant advances in nanotechnology have led to an increasing production of nanomaterial dependent products in a variety of fields such as pharmaceutical, medical diagnosis, and food packaging.

In recent years, the synthesis of graphene and its derivatives has increased as Graphene Family Nanomaterials (GFNs), including multi-layer and single-layer graphene, graphene nanosheets, ribbon, graphene oxide (GO), and revived graphene oxide (rGO) (1). GO is one of the important derivatives of graphene family whose unique properties such as low toxicity, unique shape and geometry, high biomaterial loading ability, and simple and low-cost synthesis have made it useful in transferring medications, proteins and genes, such that it has been extensively used in pharmaceutical and medical fields in recent years (2). Given the increasing development of products containing nanographene oxide and increasing exposure of humans and the environment to these products, their standardization and safety assessment are highly important (3-7).

Several studies have reported side-effects of nanoparticles on human health and the environment. The cytotoxicity of carbon nanotubes on PC12 cell line and its effect on proteins such as hemoglobin have been reported (8).

No cytotoxicity or apoptosis has been reported due to graphene oxide nanoparticles on A549 cells line, but activation of oxidative pathway and its effect on the cell line have been reported (9). In studies on the effect of size of graphene nanoparticles, nanotubes larger than $2 \mu$ m were found to enter the cell with difficulty $(10,11)$.

In the present study, the cytotoxicity and genotoxicity of single-layer graphene oxide nanosheets on colon cancer HT29 cell line were investigated by Trypan Blue and Micronucleus methods. 


\section{Methods}

\subsection{Preparation and Determination of Properties of Graphene Oxide Nanosheets}

The colloidal solution of GO nanosheets was procured from NAMAGO Company in Tehran. According to this company, the solution had been prepared by modified Hummers method (12).

The average shape and diameter of nanosheets tested were measured by Transient Electron Microscope (CM120, Philips) and their properties were assessed using IR device (Spectrum Two, Perkin Elmer).

\subsection{Preparation of different concentrations of graphene oxide nanosheets}

The colloidal solution with an initial concentration of $1000 \mu \mathrm{g} / \mathrm{mL}$ was purchased, and diluted with deionized distilled water to $10,15,25,50,100$, and $200 \mu \mathrm{g} / \mathrm{mL}$ concentrations.

\subsection{Cell Culture}

According to ISO 10993, the colon cancer HT20 cell line is a suitable cell for cytotoxicity and genotoxicity studies, which was procured from Tehran's Pasteur Institute. This cell line was cultured in RPMI-1640 (Sigma) medium containing 10\% bovine fetal serum (Sigma), $10 \mu \mathrm{g} / \mathrm{mL}$ of streptomycin, and 100 units $/ \mathrm{mL}$ of penicillin (Sigma), in a $37^{\circ} \mathrm{C}$ incubator with $5 \% \mathrm{CO}_{2}$ and $96 \%$ humidity. All cell treatments were performed in cell growth logarithmic phase.

\subsection{Cell Mortality Assessment by Trypan Blue Method}

Cell mortality rate was assessed by Trypan Blue method. HT20 cells were cultured in 6-well plates $\left(1 \times 10^{5}\right.$ cell per well) and incubated for 24 hours. Then, cell were treated with 10, 15, 25, 50, 100, and 200 $\mu \mathrm{g} /$ mLconcentrations of GO nanosheets, and one well was left untreated as negative control. The test was repeated three times. The supernatant was removed after the intended exposure periods, and cells were detached from the substrate with trypsin/EDTA. The supernatant was collected and centrifuged at 750 rcf for 5 minutes. Then, $10 \mu \mathrm{L}$ of cell suspension was added to $10 \mu \mathrm{L}$ of trypan blue, and stained in 2 - 3 minutes. Cells were counted by a Neubauer slide under an optical microscope. The cell mortality percentage was reported as the number of dead cells over the total number of cells.

\subsection{The Changes in Cell Morphology}

HT20 cell line was cultured in 24-well plates, with 20,000 cells in each well, and after 24 hours of incubation, treated for 24, 48, and 72 hours with $10,15,25,50,100$, and $200 \mu \mathrm{g} / \mathrm{mL}$ concentrations of GO nanosheets. One well was left untreated as negative control. Then, using an optical microscope, the contrast phase was observed and examined.

\subsection{Cell Ultrastructure Assessment with Electron Microscope}

Electron microscope images were examined to confirm penetration of GO nanosheets in the cell. HT20 cells were cultured in a $25 \mathrm{~cm}^{2}$ flask, and then treated with 50 $\mu \mathrm{g} / \mathrm{mL}$ concentration after incubation for 24 hours, and one untreated flask was chosen as control. After 48 hours of treatment, trypsinized cells were centrifuged at $750 \mathrm{rcf}$ for 5 minutes. They underwent primary fixation in $2.5 \%$ glutaraldehyde, and the secondary fixation in $1 \%$ osmium tetroxide, followed by dehydration in increasing concentrations of alcohol, and then embedding in epoxy resin. Next, thin sections were prepared by a microtome and examined under an electron microscope (CM120, Philips).

\subsection{Micronucleus Test}

$25 \times 10^{3}$ HT20 cells were cultured in a Petri dish. After 24 hours of incubation, they were treated with 10,15, 25, 50, 100 , and $200 \mu \mathrm{g} / \mathrm{mL}$ concentrations of GO nanosheets, and one plate was left untreated as negative control. Immediately after treatment, cytokalazin B with a final concentration of $3 \mu \mathrm{g} / \mathrm{mL}$ was added to Petri dishes, and fixed after 48 hours of incubation at $37^{\circ} \mathrm{C}$ with $5 \% \mathrm{CO}_{2}$ and $96 \%$ humidity. No significant change was observed in the culture medium $\mathrm{pH}$ in any of the Petri dishes. Cultures were duplicates in three independent repeats.

\subsection{Preparation of Slides}

After treatment period, the supernatant was removed from Petri dishes and rinsed in cold PSB. Then, $500 \mu \mathrm{L}$ of acetic acid/methanol (1:6) was added over 15 minutes, and pre-fixation was carried out in cool temperature. The final fixation with acetic acid/methanol (1:6) was performed in 15 minutes, and cells were stained with $20 \%$ Giesma solution. After coding, Petri dishes were examined with an optical microscope of $100 \times$ magnification.

\subsection{Nuclear Division Index (NDI) by Observation and Assess- ment of Slides}

A minimum of 500 viable cells were assessed in each sample, and cells with one, two and three nuclei were counted, and NDI was calculated according to Michael Fenck's method using the following equation: 
$\mathrm{NDI}=(\mathrm{M} 1+2 \mathrm{M} 2+3 \mathrm{M} 3+4 \mathrm{M} 4) / \mathrm{N}_{\mathrm{t}}$

Where: N1 - N4 are cells with one, two, three or four nuclei and $\mathrm{N}$ is total number of viable cells.

\subsection{Micronucleus Analysis}

Micronucleus was assessed with a minimum of 1000 binucleate cells counted with an optical microscope of 100 $\times$ magnification.

To micronucleus frequency, cells in cytokinesis should have the following features: be binucleate (BN); have intact nucleus membrane, or be in one cytoplasmic area; both nuclei should have similar staining pattern and intensity; both nuclei may be connected via a fine nucleoplasmic bridge, which should not be wider than 1/4 of nucleus diameter; the two main nuclei in a cell may be touching, but should not overlay each other; cytoplasmic area with a BN cell membrane should be intact, and clearly distinct from an adjacent cytoplasmic area.

\subsection{Nucleoplasmic Bridges and Nuclear Buds}

To assess NPBs and NBUDs, a minimum of $1000 \mathrm{BN}$ cells were counted using an optical microscope of $100 \times$ magnification. Structures attached to nucleus, not wider than 1/4 of nucleus diameter, with similar staining patterns and intensity are known as nucleoplasmic bridges (NPBs). In terms of shape and staining intensity, Nuclear Buds are similar to micronuclei, which are connected to the nucleus via a bridge narrower than a bud or a very narrow bridge. Thomas et al. proposed that MPBs/MN ratio is indicative of the type of abnormalities formed, such that the total number of NPBs in a treated cell over the total MN in the same cell shows aneugenicity or clastogenicity of abnormalities. When aneugenicity dominates clastogenicity, minimum NPBs is formed and NPBs/MN tends to zero, and when clastogenicity dominates, this ratio exceeds 0.7 , which can be assessed by Centromere Probe method (13).

\subsection{Statistical Method}

Data obtained are presented as mean \pm SD, and analyses were carried out in SPSS using student t-test at significance levels of $\mathrm{P} \leq 0.05$ and $\mathrm{P} \leq 0.01$, and graphs were plotted by Excel.

\section{Results}

\subsection{Graphene Oxide Nanosheets Characteristics}

Characteristics of GO nanosheets such as size and diameter were determined using a transient electron microscope. Length of single-layer nanosheets was reported in these images as 3- $6 \mu \mathrm{m}$ with diameter $<1 \mathrm{~nm}$. IR results indicate proper oxidation of GO nanosheets. Characteristics of GO nanosheets are presented in Table 1, and electron microscope images and IR graphs are shown in Figure 1 and Figure 2, respectively.

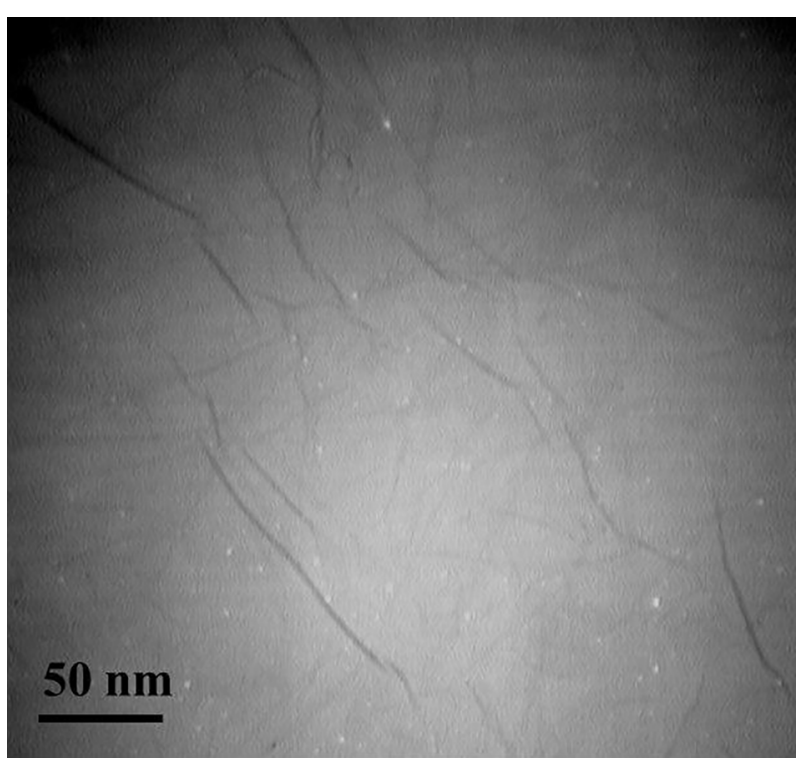

Figure 1. Graphene oxide nanosheet images by transient electron microscope

\subsection{Cell Mortality by Trypan Blue Method}

Membrane integrity was preserved in assessing cell mortality by Trypan blue method. Trypan blue stain passes through membrane of damaged and dead cells, and thus these cells are seen in blue and viable cells with intact membranes are seen in transparent colors. The results presented in Figure 2 show an increase in cell mortality with increasing concentration of nanoparticles and treatment time, with a significant difference compared to control in all concentrations and times $(24,48$, and 72 hours) with the exception of $10 \mu \mathrm{g} / \mathrm{mL}$ in 24 hours $\left(\mathrm{P} \leq 0.05^{*}\right)$. The highest cell mortality rate was observed in different concentrations and treatment time of 72 hours. The results showed $50 \%$ cell mortality $\left(\mathrm{IC}_{50}\right.$ ) at concentration of $50 \mu \mathrm{g} / \mathrm{mL}$ and treatment times of 24,48 , and 72 hours. The results are shown as mean \pm SD in three independent repeats.

\subsection{Changes in Cell Morphology}

Cell morphology assessment is an important indicator in cell studies. Changes in HT20 morphology following exposure to different concentrations of GO nanosheets at 24,48 , and 72 hours to show cytotoxicity effects of GO nanosheets compared to untreated samples are shown (Figure 3A, B, C, and D). Dramatic changes are observed in the cells morphology such as: cell wrinkling, cytoplasmic 
Table 1. Graphene Oxide Nanosheets Characteristics

\begin{tabular}{lccccc}
\hline Sample & Concentration, $\mu \mathrm{g} / \mathbf{m L}$ & Size (TEM) Length and Width, $\mu \mathbf{m}$ & Size (TEM) Diameter, nm & Coverage & Shape \\
\hline Graphene oxide & 1000 & $3-6$ & $\leq 1$ & None & Single-layer nanosheets \\
\hline
\end{tabular}

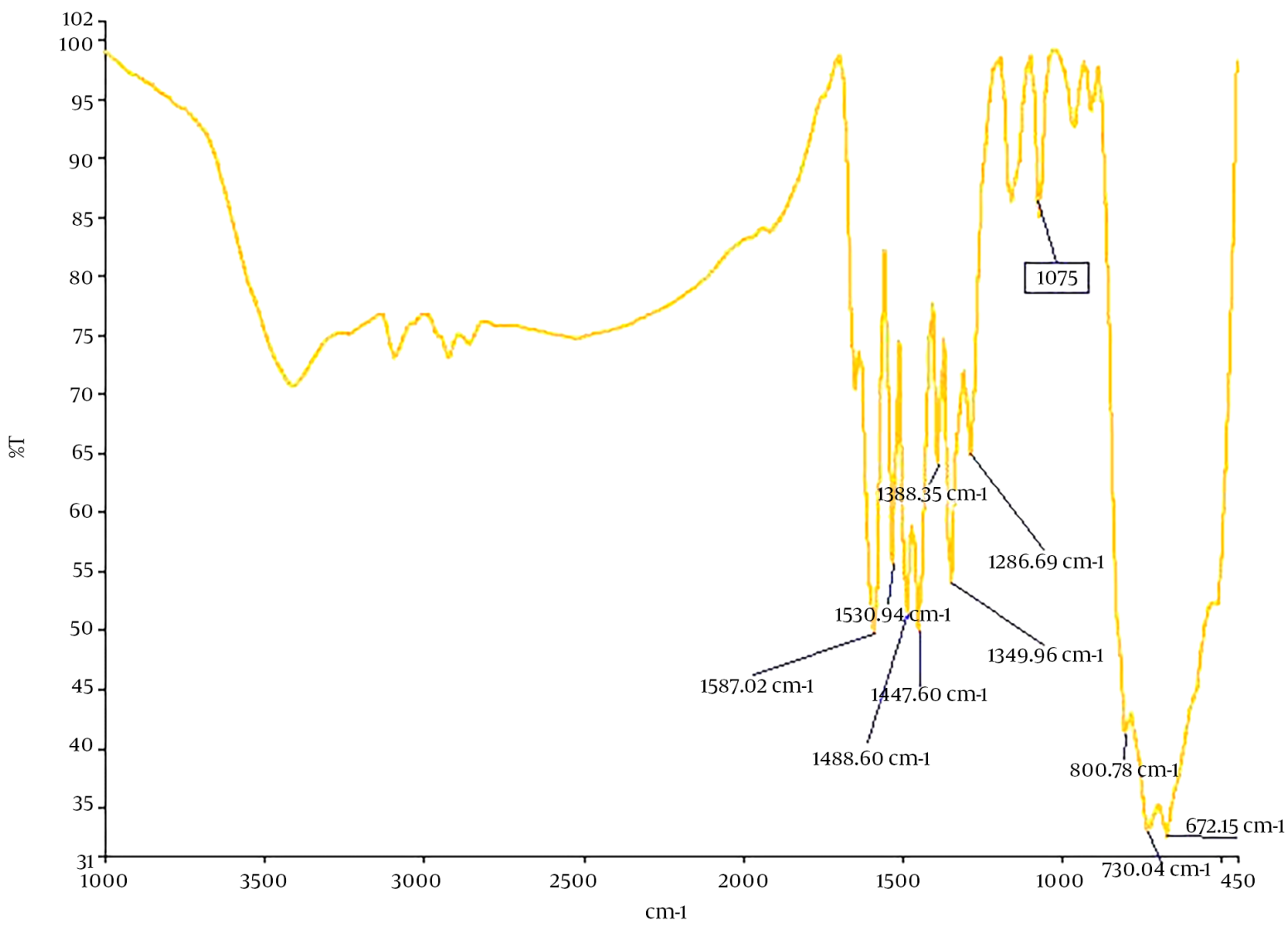

Figure 2. IR graph of GO nanosheets

degeneration, nucleus pigmentation, and permeability of membrane at $\mathrm{IC}_{50}$ concentration, and images reported show time-dependency of the induced effects. No induced effects were observed at lower concentrations than $\mathrm{IC}_{50}$ compared to untreated sample.

\subsection{Electron Microscope Examination of Cell Ultrastructure}

Electron microscope images show that GO nanosheets have not penetrated the cell and are observed around membrane in agglomerated form.

\subsection{Micronucleus Test}

The results in Figure 5 show a reduction in concentration-dependent NDI. The results are reported as mean \pm SD in three independent repeats in 1500 cells, and show significant differences compared to control sample in all concentrations $\left(\mathrm{P} \leq 0.05^{*}\right)$.

An increase in concentration-dependent micronucleus count is also observed, which is significantly different compared to control at $10 \mu \mathrm{g} / \mathrm{mL}$ with $\mathrm{P} \leq 0.05$ and at 15,25 , and $50 \mu \mathrm{g} / \mathrm{mL}$ with $\mathrm{P} \leq 0.01^{* *}$. The results are shown as mean \pm SD in three independent repeats with 3000 BN cells.

MN and NBUDs counts were performed with $1000 \mathrm{BN}$ cells. As shown in Figure 5, MN and NBUDs counts increase with increasing concentration, with a significant difference from control sample $\left(\mathrm{P} \leq 0.05^{*}\right)$. The results are shown as mean \pm SD in three independent repeats with 3000 BN cells. 

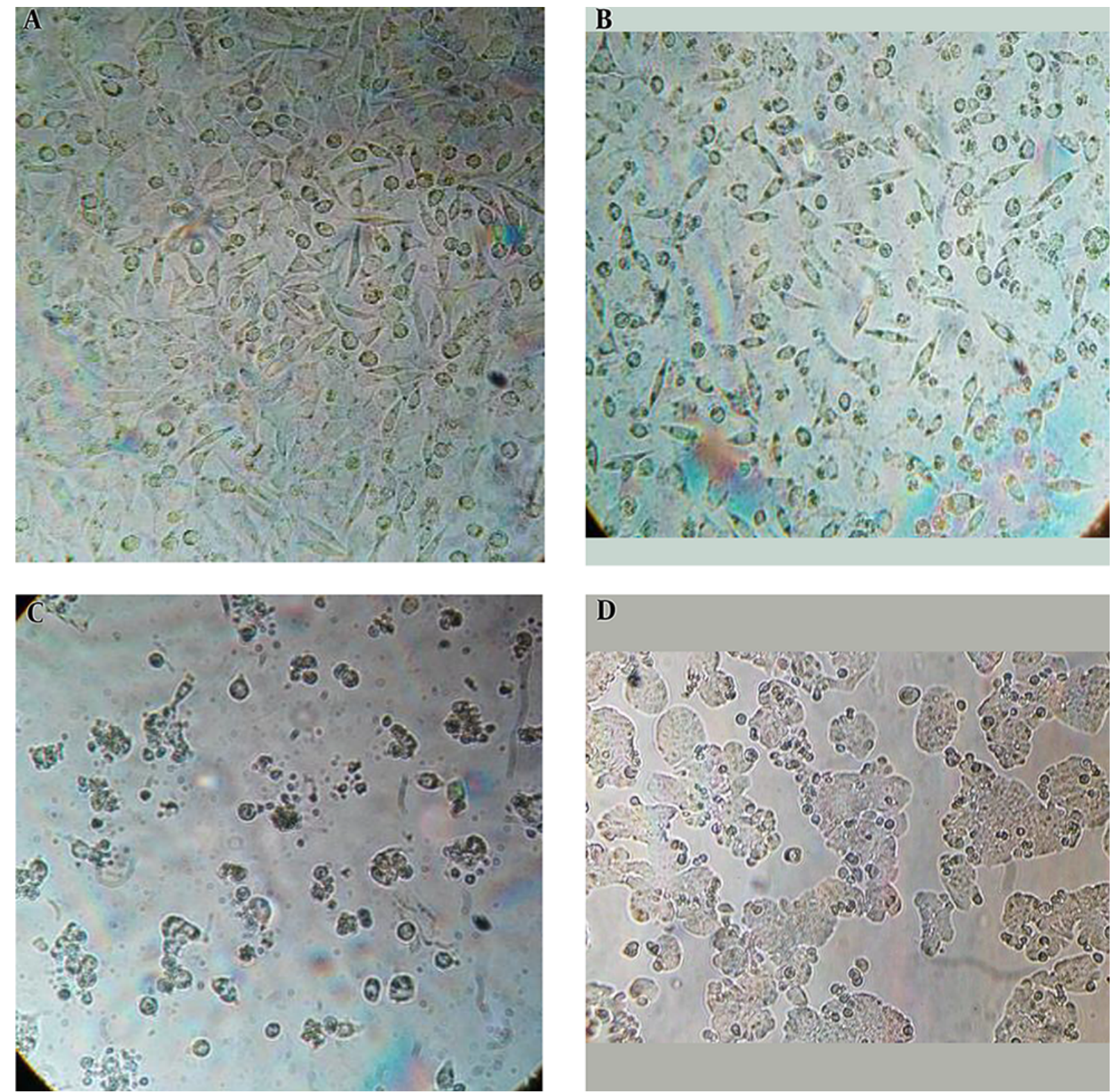

Figure 3. Optical microscope contrast phase images of HT20 treated with GO nanosheets at $\mathrm{IC}_{50}$ concentration after 24 hours (A), 48 hours (B), and 72 hours (C), and untreated cells

\section{Discussion}

Nanomaterials possess unique physicochemical properties and have applications in a variety of fields. Studies have revealed their different biological properties in invitro and in-vivo conditions, which determine the role and application of nanomaterials (1).

In recent years, graphene and its derivatives have been substantially used for their unique properties in differ- ent fields such as medication delivery/therapy, laboratory equipment, etc. Many studies conducted on graphene family have shown contradictory results regarding their biocompatibility or otherwise (1-8).

The present study investigated cytotoxicity and genotoxicity of GO nanosheets in colon cancer HT20 cell line. Trypan blue test was used to determine $\mathrm{IC}_{50}$ concentration, and then concentrations less than that were chosen in assessing genotoxicity. As discussed in the results section, 50 


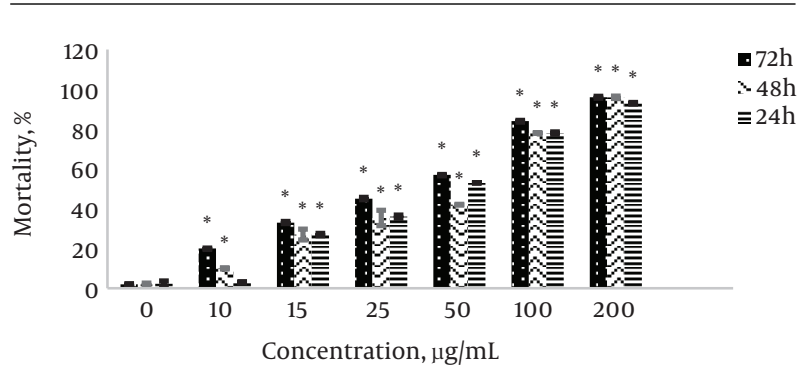

Figure 4. The effect of GO nanosheets on HT20 cell mortality at different concentrations and treatment times of 24,48 , and 72 hours. $P \leq 0.05$ was taken as significant $\left(\mathrm{P} \leq 0.05^{*}\right)$. The results are reported as percentage of cell mortality compared to control and presented as mean $\pm \mathrm{SD}$.

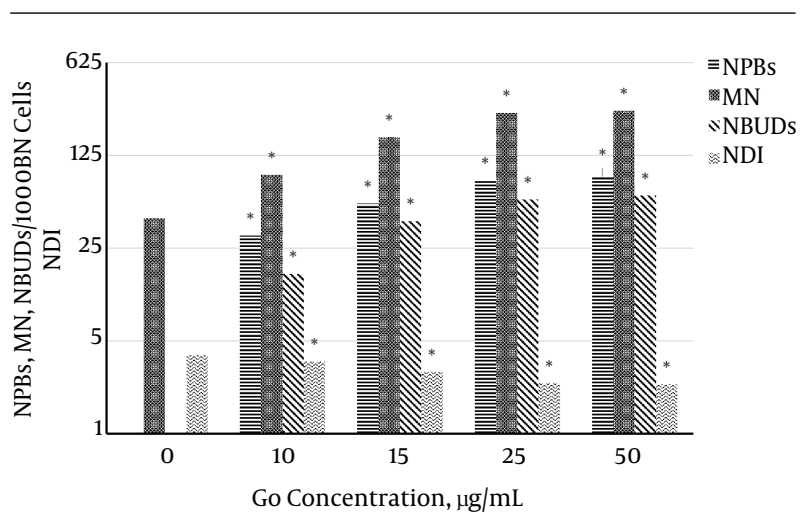

Figure 5. MN, NPBs, NBUDs counts, and NDI in BN cells. $\mathrm{P} \leq 0.05$ was taken as sig nificant $\left(\mathrm{P} \leq 0.01^{* *}, \mathrm{P} \leq 0.05^{*}\right)$.

$\mu \mathrm{g} / \mathrm{mL}$ concentration of GO nanosheets was determined as $\mathrm{IC}_{50}$, and genotoxicity was assessed by micronucleus test at concentrations of $10,15,25$, and $50 \mu \mathrm{g} / \mathrm{mL}$. Micronucleus is a sensitive and reliable test for cytotoxicity and genotoxicity. NDI result was used in assessing the reduction in cell proliferation and cytotoxicity, and micronucleus frequency results of NPBs and NBUDs were used in assessing genotoxicity.

The significant reduction in NDI compared to control at all concentrations indicated delayed cell cycle, and the lowest cell proliferation rate was observed at $50 \mu \mathrm{g} / \mathrm{mL}$. According to Trypan blue results, $50 \mu \mathrm{g} / \mathrm{mL}$ was reported as $\mathrm{IC}_{50}$, at which significant changes in cell morphology were observed including cell wrinkling, cytoplasmic degradation, nucleus pigmentation, and membrane permeability. According to NDI data, a significant reduction in NDI of $40 \%$ compared to control was reported ( $\mathrm{P} \leq 0.05$ ).

Micronucleus is a reliable and effective method for direct and indirect assessment of cell and DNA damage. Micronuclei are formed due to irreparable chromosomal gaps, DNAs left behind repair, chromosomal parts with no centromere, asymmetric chromosomal rearrangement, cell cycle checkpoint defects, chromosomal instability, etc. NPBs are the result of the telomere end attachment and an indicator of de-centric chromosomes, and NBUDs are formed by genetic improvement, chromosomal instability and elimination of DNA repair complexes $(12,14)$. As discussed in the results section, with increasing concentration of GO nanosheets, significant increases are observed in NPBs and NBUDs compared to control ( $\mathrm{P} \leq 0.05$ ), indicating induced genotoxicity at concentrations less than $\mathrm{IC}_{50}$.

The electron microscope images show non-entry of GO nanosheets into the cell. Observing single-layer GO nanosheets in biological samples with transient electron microscope is very difficult, but since GO nanosheets aggregate and fold in culture medium compared to pure water, their penetration into the cell is easily visible. Go nanosheets absorb amino acids and nutrients of the culture medium, and thus induce oxidative stresses (15-17). Hence, cytotoxicity and genotoxicity are probably indirectly induced, and the damage appears to be caused by oxidative stress pathways and oxidation of nuclear molecules, which induce cytotoxicity and genotoxicity (18, 19).

In studies conducted on A540 cells with GO, their high biocompatibility was confirmed by Trypan blue, LDH test, CCK- 8 test, and apoptotic technique with Anxin kit. But an increase in ROS oxidation was observed at high concentrations and GO was recommended as a biocompatible carrier in medication transmission (8). Wang et al. reported toxicity of GO at $50 \mu \mathrm{g} / \mathrm{mL}$ and higher concentrations (20).

In a study conducted by Chang et al., no nanoparticle penetration into the cell was observed, which suggests its biocompatibility (8). In a study by Lewinski et al., Go size less than 100 - $5 \mathrm{~nm}$ was used as a carrier, and penetration into the cell was confirmed by an electron microscope (21). Moreover, in a study conducted by Wang et al., GO accumulation in fibroblast cells was reported (20). In a study on small negatively charged carbon nanotubes, easy penetration of nanoparticles into the cell was reported. But, $2 \mu \mathrm{m}$ carbon nanotubes entered the cell with difficulty (11).

In the present study, Go nanosheets did not enter the cell, but cytotoxicity was reported at concentrations greater than $50 \mu \mathrm{g} / \mathrm{mL}$, and genotoxicity was observed at lower concentrations, which was induced by oxidative stress, and therefore lack of biocompatibility of GO nanosheets was reported. The difference in these reports can be attributed to GO synthesis method and related characteristics, and also the cell model used (22-29). 


\subsection{Conclusion}

Concentration, shape, duration, physicochemical characteristics of GO such as size and shape, agglomeration, and surface chemistry have key roles in inducing cytotoxicity and genotoxicity in treated cells.

\section{References}

1. Guo X, Mei N. Assessment of the toxic potential of graphene family nanomaterials. J Food Drug Anal. 2014;22(1):105-15. doi: 10.1016/j.jfda.2014.01.009. [PubMed: 24673908].

2. Liu Z, Robinson JT, Sun X, Dai H. PEGylated nanographene oxide for delivery of water-insoluble cancer drugs. J Am Chem Soc. 2008;130(33):10876-7. doi: 10.1021/ja803688x. [PubMed: 18661992]. [PubMed Central: PMC2597374].

3. Allen MJ, Tung VC, Kaner RB. Honeycomb carbon: a review of graphene. Chem Rev. 2010;110(1):132-45. doi: 10.1021/cr900070d. [PubMed: 19610631].

4. Geim AK. Graphene: status and prospects. Science. 2009;324(5934):1530-4. doi: 10.1126/science.1158877. [PubMed: 19541989].

5. Geim AK, Novoselov KS. The rise of graphene. Nat Mater. 2007;6(3):18391. doi: $10.1038 /$ nmat1849. [PubMed: 17330084 ].

6. Hussain SM, Braydich-Stolle LK, Schrand AM, Murdock RC, Yu KO, Mattie DM, et al. Toxicity evaluation for safe use of nanomaterials: Recent achievements and technical challenges. Adv Mater. 2009;21(16):154959. doi: 10.1002/adma.200801395.

7. Syama S, Mohanan PV. Safety and biocompatibility of graphene: A new generation nanomaterial for biomedical application. Int J Biol Macromol. 2016;86:546-55. doi: 10.1016/j.ijbiomac.2016.01.116. [PubMed: 26851208]

8. Chang Y, Yang ST, Liu JH, Dong E, Wang Y, Cao A, et al. In vitro toxicity evaluation of graphene oxide on A549 cells. Toxicol Lett. 2011;200(3):201-10. doi: 10.1016/j.toxlet.2010.11.016. [PubMed: 21130147].

9. Zeinabad HA, Zarrabian A, Saboury AA, Alizadeh AM, Falahati M. Interaction of single and multi wall carbon nanotubes with the biological systems: tau protein and PC12 cells as targets. Sci Rep. 2016;6:26508. doi: 10.1038/srep26508. [PubMed: 27216374]. [PubMed Central: PMC4877924].

10. Becker ML, Fagan JA, Gallant ND, Bauer BJ, Bajpai V, Hobbie EK, et al. Cover PICTURE: LENGTH-DEPENDENT UPTAKE of DNA-wrapped single-walled carbon nanotubes (Adv. Mater. 7/2007). Adv Mater. 2007;19(7):393-45. doi:10.1002/adma.200790026.

11. Wick P, Manser P, Limbach LK, Dettlaff-Weglikowska U, Krumeich F, Roth S, et al. The degree and kind of agglomeration affect carbon nanotube cytotoxicity. Toxicol Lett. 2007;168(2):121-31. doi: 10.1016/j.toxlet.2006.08.019. [PubMed: 17169512].

12. Hummers WS, Offeman RE. Preparation of graphitic oxide. JAm Chem Soc. 1958;80(6):1339. doi: 10.1021/ja01539a017.

13. Thomas P, Umegaki K, Fenech M. Nucleoplasmic bridges are a sensitive measure of chromosome rearrangement in the cytokinesis-block micronucleus assay. Mutagenesis. 2003;18(2):187-94. doi: 10.1093/mutage/18.2.187. [PubMed: 12621075].

14. Fenech M. Cytokinesis-block micronucleus cytome assay. Nat Protoc. 2007;2(5):1084-104. doi: 10.1038/nprot.2007.77. [PubMed: 17546000].
15. Guo L, Von Dem Bussche A, Buechner M, Yan A, Kane AB, Hurt RH. Adsorption of essential micronutrients by carbon nanotubes and the implications for nanotoxicity testing. Small. 2008;4(6):721-7. doi: 10.1002/smll.200700754. [PubMed: 18504717]. [PubMed Central: PMC3209620].

16. Liu J, Yang L, Hopfinger AJ. Affinity of drugs and small biologically active molecules to carbon nanotubes: a pharmacodynamics and nanotoxicity factor? Mol Pharm. 2009;6(3):873-82. doi: 10.1021/mp800197v. [PubMed: 19281188]. [PubMed Central: PMC2689322]

17. Qin W, Li X, Bian WW, Fan XJ, Qi JY. Density functional theory calculations and molecular dynamics simulations of the adsorption of biomolecules on graphene surfaces. Biomaterials. 2010;31(5):1007-16. doi: 10.1016/j.biomaterials.2009.10.013. [PubMed: 19880174].

18. Yang ST, Wang X, Jia G, Gu Y, Wang T, Nie H, et al. Long-term accumulation and low toxicity of single-walled carbon nanotubes in intravenously exposed mice. Toxicol Lett. 2008;181(3):182-9. doi: 10.1016/j.toxlet.2008.07.020. [PubMed:18760340].

19. Pulskamp K, Diabate S, Krug HF. Carbon nanotubes show no sign of acute toxicity but induce intracellular reactive oxygen species in dependence on contaminants. Toxicol Lett. 2007;168(1):58-74. doi: 10.1016/j.toxlet.2006.11.001. [PubMed: 17141434].

20. Wang K, Ruan J, Song H, Zhang J, Wo Y, Guo S, et al. Biocompatibility of Graphene Oxide. Nanoscale Res Lett. 2011;6(1):8. doi: 10.1007/s11671010-9751-6. [PubMed: 27502632]. [PubMed Central: PMC3212228].

21. Lewinski N, Colvin V, Drezek R. Cytotoxicity of nanoparticles. Small. 2008;4(1):26-49. doi:10.1002/smll.200700595. [PubMed:18165959].

22. Wang L, Lee K, Sun YY, Lucking M, Chen Z, Zhao JJ, et al. Graphene oxide as an ideal substrate for hydrogen storage. ACS Nano. 2009;3(10):2995-3000. doi: 10.1021/nn900667s. [PubMed:19856979].

23. Zhang Y, Ali SF, Dervishi E, Xu Y, Li Z, Casciano D, et al. Cytotoxicity effects of graphene and single-wall carbon nanotubes in neural phaeochromocytoma-derived PC12 cells. ACS Nano. 2010;4(6):3181-6. doi: 10.1021/nn1007176. [PubMed: 20481456].

24. Yang X, Zhang X, Ma Y, Huang Y, Wang Y, Chen Y. Superparamagnetic graphene oxide-Fe3O4 nanoparticles hybrid for controlled targeted drug carriers. J Mater Chem. 2009;19(18):2710-4. doi: 10.1039/b821416f.

25. Zhang L, Xia J, Zhao Q, Liu L, Zhang Z. Functional graphene oxide as a nanocarrier for controlled loading and targeted delivery of mixed anticancer drugs. Small. 2010;6(4):537-44. doi: 10.1002/smll.200901680. [PubMed: 20033930].

26. Yang W, Ratinac KR, Ringer SP, Thordarson P, Gooding JJ, Braet F. Carbon nanomaterials in biosensors: should you use nanotubes or graphene? Angew Chem Int Ed Engl. 2010;49(12):2114-38. doi: 10.1002/anie.200903463. [PubMed: 20187048].

27. Scheuermann GM, Rumi L, Steurer P, Bannwarth W, Mulhaupt R. Palladium nanoparticles on graphite oxide and its functionalized graphene derivatives as highly active catalysts for the SuzukiMiyaura coupling reaction. J Am Chem Soc. 2009;131(23):8262-70. doi: 10.1021/ja901105a. [PubMed: 19469566].

28. Li N, Xia T, Nel AE. The role of oxidative stress in ambient particulate matter-induced lung diseases and its implications in the toxicity of engineered nanoparticles. Free Radic Biol Med. 2008;44(9):168999. doi: 10.1016/j.freeradbiomed.2008.01.028. [PubMed: 18313407]. [PubMed Central: PMC2387181].

29. Li W, Chen C, Ye C, Wei T, Zhao Y, Lao F, et al. The translocation of fullerenic nanoparticles into lysosome via the pathway of clathrin-mediated endocytosis. Nanotechnology. 2008;19(14):145102. doi: 10.1088/0957-4484/19/14/145102. [PubMed: 21817752]. 